\title{
Optimization of Fermentation Medium for Producing $\alpha$-Hydroxyphenylacetic Acid by Using Plackett-Burman Design and Response Surface Methodology*
}

\author{
Zhiguo Hou ${ }^{1}$, Bingmei Chen ${ }^{1}$, Jing Lan ${ }^{1}$, Yueman Liu', Xiaoping $\mathrm{Xu}^{1 \#}$, James Yu Gu${ }^{2}, J^{1}$ jie Gu ${ }^{3}$ \\ Collage of Chemistry and Chemical Engineering, Fuzhou University, Fujian, Fuzhou, China \\ ${ }^{2}$ Department of Chemical Engineering, University of Ottawa, Ottawa, Canada \\ ${ }^{3}$ Department of Mechanical and Aerospace Engineering, Carleton University, Ottawa, Canada \\ Email: ${ }^{*} x u @$ fzu.edu.cn
}

Received May 9, 2013; revised June 9, 2013; accepted July 10, 2013

Copyright (C) 2013 Zhiguo Hou et al. This is an open access article distributed under the Creative Commons Attribution License, which permits unrestricted use, distribution, and reproduction in any medium, provided the original work is properly cited.

\begin{abstract}
Plackett-Burman design and response surface methodology were applied in order to optimize the fermentation medium of (R)- $\alpha$-hydroxyphenylacetic acid ((R)-HPA) producing Bacillus sp. HZG-19. The factors playing important roles in the production of (R)-HPA were selected based on Plackett-Burman design. The path of steepest ascent was undertaken to optimize said fermentation medium. Finally, the optimal levels of the factors with the greatest change in regard to product yield were further optimized using Box-Behnken and response surface analysis. The optimal conditions were found to be as follows: casein peptone $30.49\left(\mathrm{~g} \times \mathrm{L}^{-1}\right)$, glycerol $14.09\left(\mathrm{~g} \times \mathrm{L}^{-1}\right), \mathrm{KH}_{2} \mathrm{PO}_{4} 0.1345\left(\mathrm{~g} \times \mathrm{L}^{-1}\right), \mathrm{K}_{2} \mathrm{HPO}_{4}$ $0.01\left(\mathrm{~g} \times \mathrm{L}^{-1}\right), \mathrm{CaCl}_{2} 0.1\left(\mathrm{~g} \times \mathrm{L}^{-1}\right), \mathrm{MnSO}_{4} 0.01\left(\mathrm{~g} \times \mathrm{L}^{-1}\right)$. Under the optimal conditions described above, the yield of (R)-HPA reached $63.30 \%$, which indicated an increase of $14.9 \%$, as compared to the yield obtained before optimization.
\end{abstract}

Keywords: $\alpha$-Hydroxyphenylacetic Acid; Fermentation Medium; Biotransformation; Response Surface Analysis

\section{Introduction}

$\alpha$-Hydroxyphenylacetic acid (mandelic acid) (HPA) and its derivatives are key intermediates for the production of various pharmaceuticals, such as semi-synthetic penicillins and cephalosporins [1-3]. It is also used as a chiral resolving agent and chiral synthon for the synthesis of anti-tumor and anti-obesity agents [4]. Many methods have been reported for the preparation of enantiomerically pure (S)-or (R)- $\alpha$-Hydroxyphenylacetic acid [5-9]. For example, the synthesis of enantiopure $\alpha$-Hydroxyphenylacetic acid has been investigated through diastereomeric crystallization [10]. It has also been prepared by the chemo-enzymatic routes [11], from methyl mandelate by lipase-catalyzed hydrolysis [12], or from kinetic resolution [13]. However, these approaches are limited in their industrial application due to the expensive catalysts, limited efficiency and low yields.

\footnotetext{
*The work was supported by the Doctoral Fund of Ministry of Education (No. 20103514110002) and the Major Plan Project of Science and Technology of Fujian Province (No. 2009N0046).

${ }^{\#}$ Corresponding author.
}

Recently we have reported a new bacterial strain, $B a-$ cillus sp. HZG-19, which is capable of degrading phenylglyoxylic acid (PGA) and affording (R)-HPA with high optical purity. Numerous variables will have an effect on the production of HPA, hence, factors playing important roles in the production of pure enantimomeric (R)-HPA are crucial for large scale production. Plackett-Burman, Box-Behnken design and response surface methodology are inexpensive and accurate methods for further optimization of the fermentation medium.

\section{Materials and Methods}

\subsection{Strain and Chemicals}

The strain (Bacillus sp. HZG-19) was preserved in the lab of Chemical Engineering Department, Fuzhou University. (R)-HPA and (S)-HPA were purchased from Sigma (St. Louis, MO USA). Phenylglyoxylic acid (PGA, $>98 \%$ ) was supplied by Pharmaceutical \& Chemical Co., Ltd of Taizhou, China. Methyl alcohol of HPLC grade was purchased from Merck, Germany. Hydroxypropyl- 
$\beta$-cyclodextrin (HP- $\beta$-CD) was supplied by Fluka (Neu Ulm, Germany). All other chemicals were obtained from local suppliers and of reagent grade.

\subsection{Medium}

Seed medium $\left(\mathrm{g} \times \mathrm{L}^{-1}\right)$ : casein peptone 10 , beef extract 5 , maltose $10, \mathrm{NaCl}_{2}, \mathrm{pH} 7.2$.

Fermentation medium $(\mathrm{FM})\left(\mathrm{g} \times \mathrm{L}^{-1}\right)$ : casein peptone 20, glycerol 10, $\mathrm{K}_{2} \mathrm{HPO}_{4} 0.01, \mathrm{KH}_{2} \mathrm{PO}_{4} 0.1, \mathrm{CaCl}_{2}$ 0.1, $\mathrm{MnSO}_{4}$ 0.01, pH 7.2.

Medium for slant culture (SM): same as seed medium with $2 \%(\mathrm{w} / \mathrm{v})$ of agar.

\subsection{Culture Conditions}

The strain, Bacillus sp. HZG-19, was inoculated into 20 $\mathrm{ml}$ seed medium in $50 \mathrm{ml}$ Erlenmeyer flasks and cultured aerobically at $32^{\circ} \mathrm{C}$ on a shaker $(180 \mathrm{rpm})$. When the cells reached logarithmic phase, cultures were then inoculated $(1 \%, \mathrm{v} / \mathrm{v})$ into $50 \mathrm{ml}$ flasks containing $20 \mathrm{ml}$ of FM medium at the same fermentation conditions. PGA solution, with a final concentration of $15 \mathrm{mM}$, was added directly into the fermentation broth under aseptic conditions. After $24 \mathrm{~h}$ of incubation, the supernatant that was obtained after centrifugation from the medium and was subjected to HPLC analysis and HPCE analysis to determine the concentration and purity of the HPA generated.

\subsection{Analytical Methods}

The concentrations of substrate and product were determined by HPLC using a reverse phase column (Agilent HC-C 18, Ø $4.6 \mathrm{~mm} \times 250 \mathrm{~mm}, 5 \mu \mathrm{m}$ ). The mobile phase is composed of methanol and phosphate buffer (25 $\mathrm{mmol} / \mathrm{L})(15: 85, \mathrm{v} / \mathrm{v})$ containing $6 \mathrm{mmol} / \mathrm{L}$ of tetrabutylammonium bromide ( $\mathrm{pH} \mathrm{6.8)}$ at the rate of $1.0 \mathrm{ml} / \mathrm{min}$. A UV detector (at $220 \mathrm{~nm}$ ) was employed for quantification.

The yield of HPA is expressed as:

$$
\text { Yield }(\%)=\mathrm{CHPA} / \mathrm{CPGA} \times 100 \% \text {, }
$$

where CHPA and CPGA represent the concentration of the HPA generated and initial concentration of PGA, respectively. The concentration of (R)-HPA and (S)-HPA were determined by HPCE. Detection was made at 214 $\mathrm{nm}$ using a buffer solution of Tris-phosphoric acid (100 $\mathrm{mmol} / \mathrm{L}, \mathrm{pH} 7.6$ ) containing $150 \mathrm{~g} / \mathrm{L}$ of hydroxypropyl$\beta$-cyclodextrin. A voltage of $20 \mathrm{KV}$ was applied at a temperature of $20^{\circ} \mathrm{C}$.

$$
\begin{aligned}
& \text { Enantiomeric excess }(\text { e.e. \%) } \\
& =([\mathrm{R}]-[\mathrm{S}]) /([\mathrm{R}]+[\mathrm{S}]) \times 100 \%,
\end{aligned}
$$

where $[R]$ and $[S]$ are the concentration of (R)-HPA and
(S)-HPA, respectively.

\section{Results and Discussion}

\subsection{Plackett-Burman Design}

The Plackett-Burman (PB) design is extremely useful in screening and selecting for the most vital factors within a large candidate pool [14]. The experiments were carried out according to the design matrix shown in Table 1, with each row representing one trial while each column represents a single variable. The six factors listed are: casein peptone, glycerol, $\mathrm{KH}_{2} \mathrm{PO}_{4}, \mathrm{~K}_{2} \mathrm{HPO}_{4}, \mathrm{CaCl}_{2}$, $\mathrm{MnSO}_{4}$, respectively. Three variables $\left(\mathrm{X}_{4}, \mathrm{X}_{6}, \mathrm{X}_{8}\right)$ are dummy variables employed to evaluate the standard errors of the experiment. Elements $(1)$ and $(-1)$ are representative of the relative amounts each variable factor, either high or low, within each experimental trial. Yield of HPA is considered as response value.

Levels selection and significance evaluation of experimental variables are summarized in Table 2. Generally, effects with a confidence level of greater than $95 \%$ are considered to be actual effects, whereas a confidence level of less than $95 \%$ indicates that the effect may have resulted due to chance. As shown in Table 2, the confidence level of factors casein peptone $\left(\mathrm{X}_{1}\right)$, glycerol $\left(\mathrm{X}_{2}\right)$ and $\mathrm{KH}_{2} \mathrm{PO}_{4}\left(\mathrm{X}_{3}\right)$ are shown to be above $95 \%$ and considered to be significant. The rest of the factors, $\mathrm{K}_{2} \mathrm{HPO}_{4}$ $\left(\mathrm{X}_{5}\right), \mathrm{CaCl}_{2}\left(\mathrm{X}_{7}\right)$ and $\mathrm{MnSO}_{4}\left(\mathrm{X}_{9}\right)$ had a confidence of below $95 \%$ in HPA production and hence, were considered insignificant. The high level of $\mathrm{X}_{5}, \mathrm{X}_{7}$ and the low level of $\mathrm{X}_{9}$ were selected during further optimization studies.

Table 1. Design matrix and experimental results of Plackett-Burman design.

\begin{tabular}{ccccccccccc}
\hline Run & $\mathrm{X}_{1}$ & $\mathrm{X}_{2}$ & $\mathrm{X}_{3}$ & $\left(\mathrm{X}_{4}\right)$ & $\mathrm{X}_{5}$ & $\left(\mathrm{X}_{6}\right)$ & $\mathrm{X}_{7}$ & $\left(\mathrm{X}_{8}\right)$ & $\mathrm{X}_{9}$ & $\mathrm{Yield} / \%$ \\
\hline 1 & 1 & -1 & 1 & -1 & -1 & -1 & 1 & 1 & 1 & 59.52 \\
2 & 1 & 1 & -1 & 1 & -1 & -1 & -1 & 1 & 1 & 60.71 \\
3 & -1 & 1 & 1 & -1 & 1 & -1 & -1 & -1 & 1 & 52.83 \\
4 & 1 & -1 & 1 & 1 & -1 & 1 & -1 & -1 & -1 & 61.72 \\
5 & 1 & 1 & -1 & 1 & 1 & -1 & 1 & -1 & -1 & 62.34 \\
6 & 1 & 1 & 1 & -1 & 1 & 1 & -1 & 1 & -1 & 61.31 \\
7 & -1 & 1 & 1 & 1 & -1 & 1 & 1 & -1 & 1 & 56.63 \\
8 & -1 & -1 & 1 & 1 & 1 & -1 & 1 & 1 & -1 & 54.02 \\
9 & -1 & -1 & -1 & 1 & 1 & 1 & -1 & 1 & 1 & 42.12 \\
10 & 1 & -1 & -1 & -1 & 1 & 1 & 1 & -1 & 1 & 51.32 \\
11 & -1 & 1 & -1 & -1 & -1 & 1 & 1 & 1 & -1 & 51.90 \\
12 & -1 & -1 & -1 & -1 & -1 & -1 & -1 & -1 & -1 & 45.05 \\
\hline
\end{tabular}

Each experiment was performed in triplicates, the same below. 
Table 2. Levels selection and significance evaluation of experimental variables.

\begin{tabular}{cccccc}
\hline \multirow{2}{*}{ Code } & \multicolumn{2}{c}{ Levels } & \multirow{2}{*}{ T-test } & $\operatorname{Pr}>|\mathrm{t}|$ & Significancy \\
\cline { 2 - 3 } & Low $(-1)$ & High (1) & & & \\
\hline $\mathrm{X}_{1}$ & 20 & 30 & 13.1833 & 0.0057 & $1^{*}$ \\
$\mathrm{X}_{2}$ & 10 & 15 & 7.7648 & 0.0162 & $3^{*}$ \\
$\mathrm{X}_{3}$ & 0.1 & 0.15 & 7.9100 & 0.0156 & $2^{*}$ \\
$\mathrm{X}_{5}$ & 0.01 & 0.015 & -2.8302 & 0.1054 & 6 \\
$\mathrm{X}_{7}$ & 0.1 & 0.15 & 2.9269 & 0.0996 & 5 \\
$\mathrm{X}_{9}$ & 0.01 & 0.015 & -3.2172 & 0.0845 & 4 \\
\hline
\end{tabular}

"Indicate that the significancy is of more than $95 \%$ confidence.

\subsection{Steepest Ascent Design to Approach the Optimal Region}

The steepest ascent method was applied in order to investigate optimal substrate concentration, by slowly increasing substrates along the path of steepest ascent until no further increase in response is observed [15]. Based on the experimental results of $\mathrm{PB}$, casein peptone, glycerol and $\mathrm{KH}_{2} \mathrm{PO}_{4}$ should be increased due to their positive effect (positive value for $\mathrm{t}$ ). Table 3 represents the design and results of the steepest ascent search experiment. As shown in Table 3, optimal fermentation medium should be around run 2, so the level of run 2 is considered as center point in the follow-up response surface experiment.

\subsection{Response Surface Analysis (RSM) and Establishment of Optimum Fermentation Medium}

RSM is a statistical method by which one can find the best conditions in a multi-factor system [16]. Among RSM, Box-Behnken design (BBD) method and central composite design are more frequently used than the others. When the number of the experimental factors does not exceed 5, Box-Behnken method is more economic. Casein peptone, glycerol and $\mathrm{KH}_{2} \mathrm{PO}_{4}$ were determined to be the main factors as shown through the PB experiment.

$\mathrm{X}_{1}, \mathrm{X}_{2}, \mathrm{X}_{3}$ represent casein peptone, glycerol, $\mathrm{KH}_{2} \mathrm{PO}_{4}$ respectively and the yield of HPA shows the response value. Factor levels were determined by steepest ascent experiment. In order to investigate the optimum levels of those variables and study their interactions, a three-factor three-level BBD was applied.

A total of 15 experiments were performed in triplicates, 12 of which used different factors while 3 trials were used as controls. Controls were used to estimate experimental error. Table 4 illustrates the coded and non-coded values of the experimental variables, with results of the BBD experiments given in Table 5.
Table 3. Design and results of the steepest ascent search experiment.

\begin{tabular}{ccccc}
\hline Run & casein peptone $(\mathrm{g} / \mathrm{L})$ & glycerol $(\mathrm{g} / \mathrm{L})$ & $\mathrm{KH}_{2} \mathrm{PO}_{4}(\mathrm{~g} / \mathrm{L})$ & Yield $(\%)$ \\
\hline 1 & 25 & 12.5 & 0.125 & 54.12 \\
2 & 28 & 13.5 & 0.135 & 61.92 \\
3 & 31 & 14.5 & 0.145 & 59.37 \\
4 & 34 & 15.5 & 0.155 & 54.10 \\
5 & 37 & 16.5 & 0.165 & 52.35 \\
\hline
\end{tabular}

Table 4. The coded and non-coded values of the experimental variables.

\begin{tabular}{ccccc}
\hline \multirow{2}{*}{ Factors } & Code & \multicolumn{3}{c}{ Coded level } \\
\cline { 3 - 5 } & & -1 & 0 & 1 \\
\hline casein peptone $(\mathrm{g} / \mathrm{L})$ & $\mathrm{X}_{1}$ & 25 & 28 & 31 \\
glycerol $(\mathrm{g} / \mathrm{L})$ & $\mathrm{X}_{2}$ & 12.5 & 13.5 & 14.5 \\
$\mathrm{KH}_{2} \mathrm{PO}_{4}(\mathrm{~g} / \mathrm{L})$ & $\mathrm{X}_{3}$ & 0.125 & 0.135 & 0.145 \\
\hline
\end{tabular}

Table 5. Design and results of BBD experiments.

\begin{tabular}{ccccc}
\hline Run & $\mathrm{X}_{1}$ & $\mathrm{X}_{2}$ & $\mathrm{X}_{3}$ & Yield/\% \\
\hline 1 & -1 & -1 & 0 & 55.53 \\
2 & -1 & 1 & 0 & 57.04 \\
3 & 1 & -1 & 0 & 56.3 \\
4 & 1 & 1 & 0 & 62.43 \\
5 & 0 & -1 & -1 & 54.13 \\
6 & 0 & -1 & 1 & 50.39 \\
7 & 0 & 1 & -1 & 56.06 \\
8 & 0 & 1 & 1 & 56.89 \\
9 & -1 & 0 & -1 & 52.78 \\
10 & 1 & 0 & -1 & 58.78 \\
11 & -1 & 0 & 1 & 52.68 \\
12 & 1 & 0 & 1 & 56.42 \\
13 & 0 & 0 & 0 & 61.83 \\
14 & 0 & 0 & 0 & 62.02 \\
15 & 0 & 0 & 0 & 61.93 \\
\hline
\end{tabular}

Based on the experimental results of BBD (Table 5) and regression analysis, a quadratic polynomial equation was established to identify the relationship between yield and variables. The model of coded units can be expressed as:

$$
\begin{aligned}
\mathrm{Y}_{1}= & 61.92667+1.9875 \mathrm{X}_{1}+2.00875 \mathrm{X}_{2} \\
& -0.67125 \mathrm{X}_{3}-1.652083 \mathrm{X}_{1}^{2}+1.155 \mathrm{X}_{1} \mathrm{X}_{2} \\
& -0.565 \mathrm{X}_{1} \mathrm{X}_{3}-2.449583 \mathrm{X}_{2}^{2}+1.1425 \mathrm{X}_{2} \mathrm{X}_{3} \\
& -5.109583 \mathrm{X}_{3}^{2}
\end{aligned}
$$

where $Y_{1}$ is the yield of HPA, $X_{1}, X_{2}$ and $X_{3}$ represent casein peptone, glycerol and $\mathrm{KH}_{2} \mathrm{PO}_{4}$, respectively. 
Analysis of variance (ANOVA) is important in determining the adequacy and significance of the quadratic model. ANOVA summary was shown in Table 6. The Fvalue of 63.1957 implies that the model was significant. A $\mathrm{p}$ value of $<0.0001$ indicated that there was only a $0.01 \%$ chance that model's large F-value could occur due to noise. Values of "prob $>$ F" less than 0.0500 indicated the significant model terms. The mathematical model

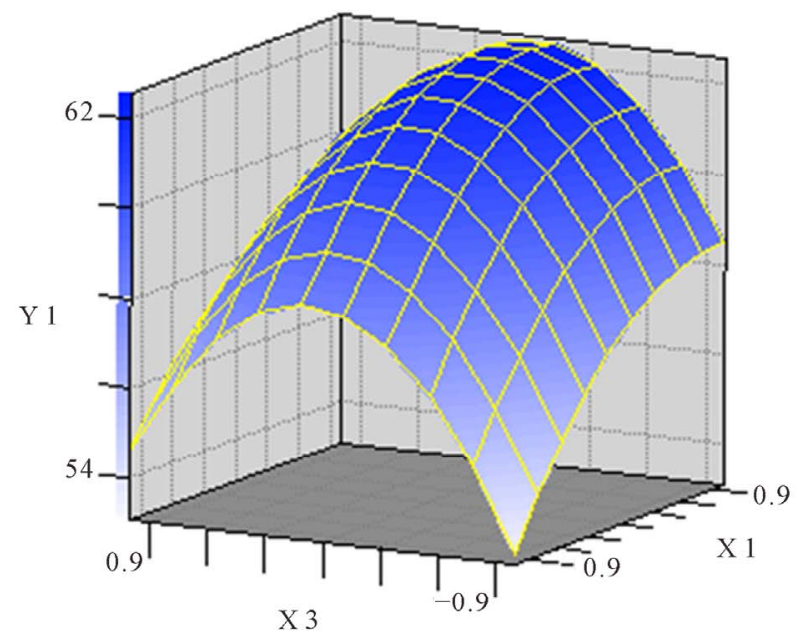

Fixed levels:

$\mathrm{X} 2=0$ was reliable with an $R^{2}$ value of 0.9913 . It suggested that model was unable to explain only $0.87 \%$ of the total variations. A low value of coefficient of the variation $(C$. $V$.$) (1.0298) clearly indicated a very high degree of pre-$ cision and a good deal of reliability of the experimental values.

Figures 1-2 show the response and contour curves for casein peptone, glycerol and $\mathrm{KH}_{2} \mathrm{PO}_{4}$. Contour curves

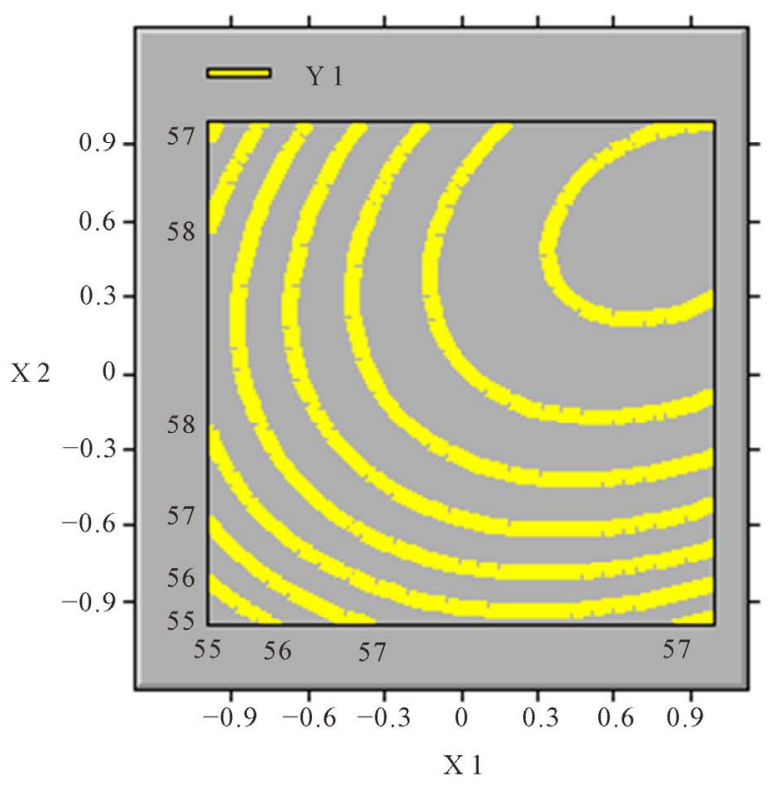

Fixed levels:

$X 3=0$

Figure 1. Response surface plot and contour plot for HPA yield (\%) as a function of casein peptone and $\mathrm{KH}_{2} \mathrm{PO}_{4}\left(\mathrm{X}_{1}\right.$ and $\mathrm{X}_{3}$ represent casein peptone and $\mathrm{KH}_{2} \mathrm{PO}_{4}$, respectively).

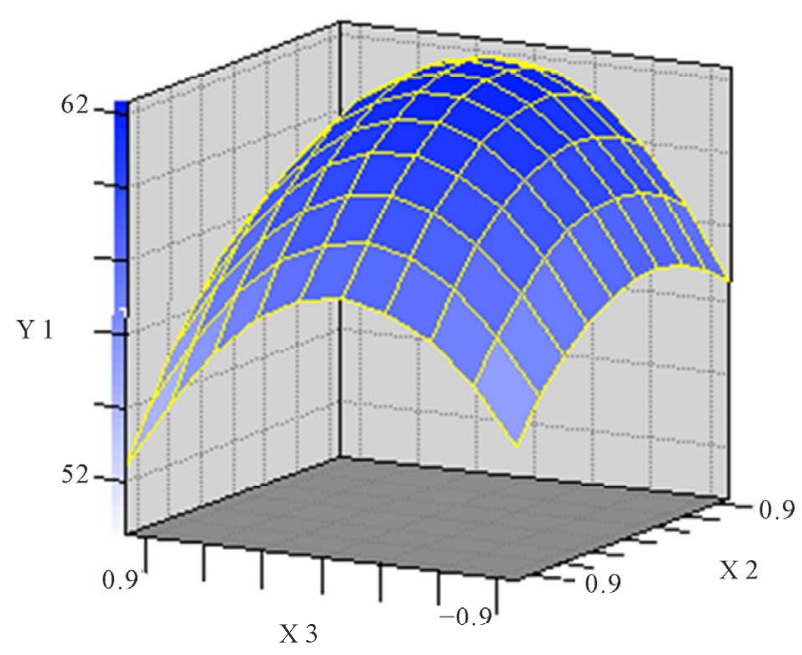

Fixed levels:

$$
\mathrm{X} 1=0
$$

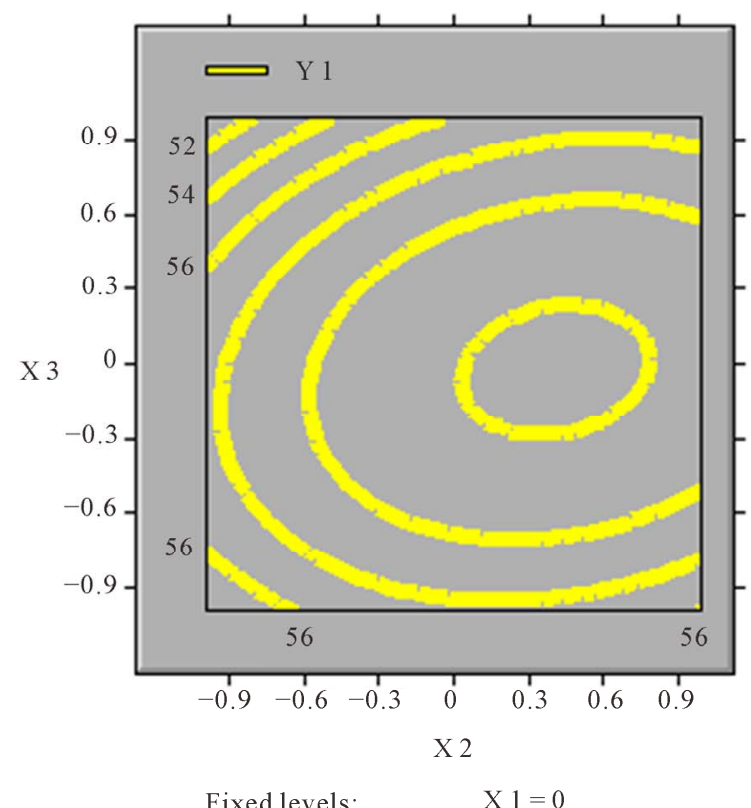

Fixed levels:

$$
\mathrm{X} 1=0
$$

Figure 2. Response surface plot and contour plot for HPA yield (\%) as a function of glycerol and $\mathrm{KH}_{2} \mathrm{PO}_{4}\left(\mathrm{X}_{2}\right.$ and $\mathrm{X}_{3}$ represent glycerol and $\mathrm{KH}_{2} \mathrm{PO}_{4}$, respectively). 
Table 6. Estimated value of regression equation partial regression coefficient and analysis of square deviation.

\begin{tabular}{|c|c|c|c|c|c|}
\hline Term & \multicolumn{2}{|c|}{$\begin{array}{c}\text { Parameter } \\
\text { estimate }\end{array}$} & tandard error & T-test & $\operatorname{Pr}>|t|$ \\
\hline $\mathrm{X}_{1}$ & \multicolumn{2}{|c|}{1.9875} & 0.2076 & 9.5750 & 0.0002 \\
\hline $\mathrm{X}_{2}$ & \multicolumn{2}{|c|}{2.0088} & 0.2076 & 9.6774 & 0.0002 \\
\hline $\mathrm{X}_{3}$ & \multicolumn{2}{|c|}{-0.6713} & 0.2076 & -3.2338 & 0.0231 \\
\hline $\mathrm{X}_{1} * \mathrm{X}_{1}$ & \multicolumn{2}{|c|}{-1.6521} & 0.3055 & -5.4071 & 0.0029 \\
\hline $\mathrm{X}_{1} * \mathrm{X}_{2}$ & \multicolumn{2}{|c|}{1.155} & 0.2936 & 3.9346 & 0.0110 \\
\hline $\mathrm{X}_{1} * \mathrm{X}_{3}$ & \multicolumn{2}{|c|}{-0.565} & 0.2936 & -1.9247 & 0.1122 \\
\hline $\mathrm{X}_{2} * \mathrm{X}_{2}$ & \multicolumn{2}{|c|}{-2.4496} & 0.3055 & -8.0173 & 0.0005 \\
\hline $\mathrm{X}_{2} * \mathrm{X}_{3}$ & \multicolumn{2}{|c|}{1.1425} & 0.2936 & 3.8920 & 0.0115 \\
\hline$X_{3} * X_{3}$ & \multicolumn{2}{|c|}{-5.1096} & 0.3055 & -16.7233 & 0.0001 \\
\hline Source & $\mathrm{DF}$ & SS & MS & F-value & Prob $>F$ \\
\hline Model & 9 & 196.0455 & 21.7828 & 63.1957 & 0.0001 \\
\hline Linear & 3 & 67.4865 & 22.4955 & 65.2633 & 0.0002 \\
\hline Quadratic & 3 & 116.7248 & 38.9083 & 112.8796 & 0.0001 \\
\hline Interaction & 3 & 11.8342 & 3.9447 & 11.4444 & 0.0112 \\
\hline Error & 5 & 1.7234 & 0.3447 & & \\
\hline Total & 14 & 197.769 & $\mathrm{R}^{2}=9 \mathrm{~S}$ & $.13 \% \mathrm{CV}$ & 1.0298 \\
\hline
\end{tabular}

represent the HPA yield as a function of concentrations of two independent variables with another variable being at a fixed level. Figure 1 shows that HPA yield increases firstly and decreases slowly afterward with the increase of casein peptone, and that moderate $\mathrm{KH}_{2} \mathrm{PO}_{4}$ results in high HPA yield. Figure 2 demonstrates that HPA yield increases firstly and then decreases slowly with decreasing glycerol, whereas moderate $\mathrm{KH}_{2} \mathrm{PO}_{4}$ caused HPA yield increasing. This could be attributed to the fact that casein peptone, $\mathrm{KH}_{2} \mathrm{PO}_{4}$ and glycerol were directly related with the activity of cell. As seen from Figures 1 and 2, there was a maximum response at the optimum level of each variable and exist the interaction among the three variables, so it was not simple linear relationship for the effect of response value.

The ridge analysis indicated that the regression equation has no singularity. Simultaneously it obtained the best response surface conditions and the predictive value of yield from the regression equation. The best theoretical levels in experiment were: $\mathrm{X}_{1}=0.816, \mathrm{X}_{2}=0.592$ and $X_{3}=-0.045$, that is, casein peptone $30.49 \mathrm{~g} \cdot \mathrm{L}^{-1}$, glycerol $14.09 \mathrm{~g} \cdot \mathrm{L}^{-1}$ and $\mathrm{KH}_{2} \mathrm{PO}_{4} 0.1345 \mathrm{~g} \cdot \mathrm{L}^{-1}$. Predicted value of yield given these conditions was $63.35 \%$. Validation under the optimized conditions was performed in a $50 \mathrm{ml}$ Erlenmeyer flask containing $20 \mathrm{ml}$ reaction medium. The experiments were conducted in triplicate. Under optimized conditions, HPA yield achieved in the verification experiment was $63.30 \%$, which was very close to the value predicted by model based on BBD (63.35\%).

\section{Conclusion}

Selective reduction of PGA with Bacillus sp. HZG-19 is a very promising technology for production of HPA. Results of this study clearly indicate that RSM is an effective method for the optimization of fermentation medium. Optimum casein peptone, glycerol and $\mathrm{KH}_{2} \mathrm{PO}_{4}$ were found to be $30.49,14.09$ and $0.1345 \mathrm{~g} \cdot \mathrm{L}^{-1}$, respectively.

\section{Acknowledgements}

This work was financially supported by the Doctoral Fund of Ministry of Education (No. 20103514110002) and the Major Plan Project of Science and Technology of Fujian Province (No. 2009N0046).

\section{REFERENCES}

[1] A. Furlenmeier, P. Quitt, K. Vogler and P. Lanz, "6-Acyl Derivatives of Aminopenicillanic Acid," US Patent No. 3957758, 1976.

[2] J. Mills, K. K. Schmiegel and W. N. Shaw, "Phenethanolamines, Compositions Containing the Same, and Method for Effecting Weight Control," US Patent No. 4391826, 1983.

[3] P. Saravanan and V. K. Singh, "An Efficient Synthesis of Chiral Nonracemic Diamines: Application in Asymmetric Synthesis," Tetrahedron Letters, Vol. 39, No. 1-2, 1998, pp. 167-170. http://dx.doi.org/10.1016/S0040-4039(97)10578-0

[4] G. D. Yadav and P. Sivakumar, "Enzyme-Catalyzed Optical Resolution of Mandelic Acid via (RS)-Methyl Mandelate in Non-Aqueous Media," Biochemical Engineering Journal, Vol. 19, No. 2, 2004, pp. 101-107. http://dx.doi.org/10.1016/j.bej.2003.12.004

[5] Y. Yamazaki and H. Maeda, "Enzymatic Synthesis of Optically Pure (r)-(-)-Mandelic Acid and Other 2-Hydroxycarbonic Acids: Screening for the Enzyme, and Its Purification, Characterization and Use," Agricultural and Biological Chemistry, Vol. 50, No. 10, 1986, pp. 26212631. http://dx.doi.org/10.1271/bbb1961.50.2621

[6] D. A. Evans, M. M. Morrissey and R. L. Dorow, "The Asymmetric Oxygenation of Chiral Imide Enolates. A General Approach to the Synthesis of Enantiomerically Pure a-Hydroxy Carboxylic Acid Synthons," Journal of the American Chemical Society, Vol. 107, No. 14, 1985, pp. 4346-4348. http://dx.doi.org/10.1021/ja00300a054

[7] S Tsuchiya, K. Miyamoto and H. Ohta, "Highly Efficient Conversion of $( \pm)$-Mandelic Acid to Its (r)-(-)-Enantiomer by Combination of Enzyme-Mediated Oxidation and Reduction," Biotechnology Letters, Vol. 14, No. 12, 1992, pp. 1137-1142. http://dx.doi.org/10.1007/BF01027017

[8] E. Takahashi, K Nakamichi and M. J. Furui, "R-(-)Mandelic Acid Production from Racemic Mandelic Acids Using Pseudomonas polycolor IFO 3918 and Micrococcus freudenreichii FERM-P 13221," Journal of Fermentation and Bioengineering, Vol. 79, No. 5, 1995, pp. 439442. http://dx.doi.org/10.1016/0922-338X(95)91258-7 
[9] B. Y. Kim, K. C. Hwang, H. S. Song, N. Chung and W. G. Bang, "Optical Resolution of rs-(+/-)-Mandelic Acid by Pseudomonas sp.," Biotechnology Letters, Vol. 22, No. 23, 2000, pp. 1871-1875.

http://dx.doi.org/10.1023/A:1005649908991

[10] E. Wehtje, P. Adlercreutz and B. Mattiasson, "Formation of C-C Bonds by Mandelonitrile Lyase in Organic Solvents," Biotechnology and Bioengineering, Vol. 36, No. 1, 1990, pp. 39-46. http://dx.doi.org/10.1002/bit.260360106

[11] J. M. Palomo, G. Fernandez-Lorente, C. Mateo, C. Ortiz, R. Fernandez-Lafuente and J. M. Guisan, "Modulation of the Enantioselectivity of Lipases via Controlled Immobilization and Medium Engineering: Hydrolytic Resolution of Mandelic Acid Esters," Enzyme and Microbial Technology, Vol. 31, No. 6, 2002, pp. 775-783. http://dx.doi.org/10.1016/S0141-0229(02)00169-2

[12] S. H. Lee, J. H. Choi, S. H. Park, J. I. Choi and S. Y. Lee, "Cell Surface Display of Lipase in Pseudomonas putida KT2442 Using OprF as an Anchoring Motif and Its Biocatalytic Applications," Enzyme and Microbial Technology, Vol. 35, No. 5, 2004, pp. 429-436. http://dx.doi.org/10.1016/j.enzmictec.2004.06.005

[13] S. H. Hsu, S. S. Wu, Y. F. Wang and C. H. Wong, "Li- pasecatalyzed Irreversible Transesterification Using Enol Esters: XAD-8 Immobilized Lipoprotein Lipase-Catalyzed Resolution of Secondary Alcohols," Tetrahedron Letters, Vol. 31, No. 44, 1990, pp. 6403-6406. http://dx.doi.org/10.1016/S0040-4039(00)97076-X

[14] G. M. Lee, E. J. Kim, N. S. Kim, S. K. Yoon, Y. H. Ahn and J. Y. Song, "Development of a Serum-Free Medium for the Production of Erythropoietin by Suspension Culture of Recombinant Chinese Hamster Ovary Cells Using a Statistical Design," Journal of Biotechnology, Vol. 69, No. 2-3, 1999, pp. 85-93.

http://dx.doi.org/10.1016/S0168-1656(99)00004-8

[15] D. C. Montogomery, "Design and Analysis of Experiments," 5th Edition, John Wiley and Sons, New York, 2001.

[16] L. J. Huang, Z. X. Lu and Y. J. Yuan, "Optimization of A Culture Medium for Cell Multiplication of Streptococcus sativarius subsp. thermophilus STX2 Using Response Surface Methodology," Food and Fermentation Industries, Vol. 31, No. 5, 2005, pp. 27-31. 